\title{
Die DEGUM gratuliert
}

Am 29. März 2014 fand in Dresden letztmalig vor der Pensionierung von Prof. Dr. med. Alfred Bunk der seit 2002 von ihm jährlich ausgerichtete Workshop zur Kontrastmittelsonografie statt. Als Referenten nahmen von internistischer Seite unter anderen Prof. W. Wermke (Charité), Dr. H.P. Weskott (Hannover), Prof. C. Görg (Marburg) und Dr. K. Stock (München) sowie von chirurgischer Seite Dr. S. Nöldeke (Garmisch-Partenkirchen) und Dr. M. Wüstner (Trier) teil.

Der damalige DEGUM-Präsident Stefan Nöldeke und der Leiter der Sektion Chir- urgie, Matthias Wüstner, nutzten die Gelegenheit, Alfred Bunk ,in Würdigung seiner Lebensleistung für die Ultraschalldiagnostik in Chirurgenhand“ eine Ehrentafel der Sektion Chirurgie zu überreichen.

Alfred Bunk nahm quasi direkt mit der Wende einen intensiven fachlichen und menschlichen Austausch nicht nur mit chirurgischen Kollegen im Westen auf und beeindruckte auch diese mit seiner zupackenden und unprätentiös kompetenten Art so stark, dass er bei nächster Gelegenheit 1999 zum Leiter der Sektion Chirurgie gewählt wurde. In diesem Amt

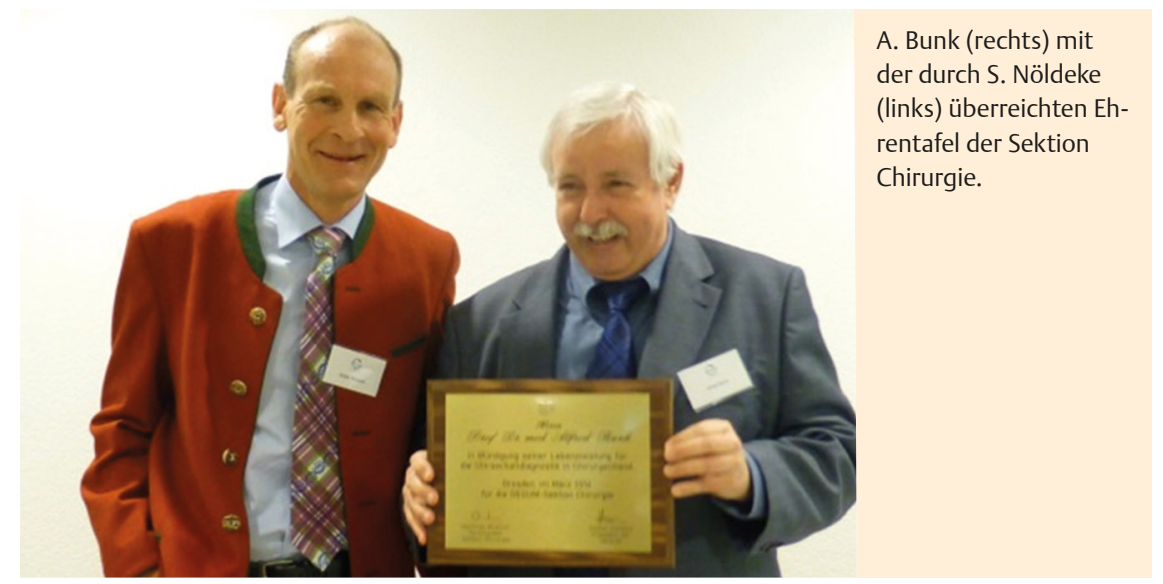

wäre er vermutlich bis heute wiedergewählt worden, wenn er nicht 2004 als erster Chirurg überhaupt in den DEGUMVorstand berufen worden wäre. Auch dort wirkte er jahrelang integrativ und kompetent, sodass er selbst nach seinem turnusgemäßen Ausscheiden aus dem Vorstand 2008, als ihm Stefan Nöldeke als Chirurg im Vorstand nachfolgte, noch weiter als Beauftragten für die „Reconquista“ der OPS-Dokumentation in die Vorstandsaktivitäten eingebunden war. Seiner beharrlichen Tätigkeit auf diesem Feld hat es die deutsche „Ultraschall-Gemeinde“ zu verdanken, dass wir in den letzten Jahren wieder erste neue OPS-Ziffern zur Erfassung von Ultraschall-Leistungen haben, die, getreu dem Thema seines jährlichen Ultraschallkurses, i.d.R. mit „komplexe differentialdiagnostische Sonografie“ beginnen und den Terminus „mit Kontrastmittel" enthalten.

Der DEGUM-Vorstand schließt sich den Glückwünschen der Sektion Chirurgie an und dankt Alfred Bunk herzlich für sein der DEGUM entgegengebrachtes Engagement.

MW, Leiter Sektion Chirurgie MG, Sekretär 